\title{
On Lewis Against Magic: A Study of Method in Metaphysics
}

DOI:

10.1007/s11229-015-0679-3

Document Version

Submitted manuscript

Link to publication record in Manchester Research Explorer

\section{Citation for published version (APA):}

Fisher, A. R. J. (2016). On Lewis Against Magic: A Study of Method in Metaphysics. Synthese, forthcoming. https://doi.org/10.1007/s11229-015-0679-3

\section{Published in:}

Synthese

\section{Citing this paper}

Please note that where the full-text provided on Manchester Research Explorer is the Author Accepted Manuscript or Proof version this may differ from the final Published version. If citing, it is advised that you check and use the publisher's definitive version.

\section{General rights}

Copyright and moral rights for the publications made accessible in the Research Explorer are retained by the authors and/or other copyright owners and it is a condition of accessing publications that users recognise and abide by the legal requirements associated with these rights.

\section{Takedown policy}

If you believe that this document breaches copyright please refer to the University of Manchester's Takedown Procedures [http://man.ac.uk/04Y6Bo] or contact uml.scholarlycommunications@manchester.ac.uk providing relevant details, so we can investigate your claim.

\section{OPEN ACCESS}




\title{
On Lewis Against Magic: A Study of Method in Metaphysics
}

\author{
A. R. J. FISHER
}

\begin{abstract}
David Lewis objected to theories that posit necessary connections between distinct entities and to theories that involve a magical grasping of their primitives. In On the Plurality of Worlds, Lewis objected to nondescript ersatzism on these grounds (and thus branded it as 'magical'). The literature contains several reconstructions of Lewis' critique of nondescript ersatzism but none of these interpretations adequately address his main argument because they fail to see that Lewis' critique is based on broader methodological considerations. I argue that a closer look at his methodology reveals the broader objection he presented against nondescript ersatzism. This objection, I further argue, remains a challenge for the ersatzer who posits structure-less entities as possible worlds.
\end{abstract}

Keywords Lewis $\cdot$ Magic $\cdot$ Method

\section{Introduction}

David Lewis objected to theories that posit necessary connections between distinct entities and to theories that involve a magical grasping of their primitives. In On the Plurality of Worlds, Lewis objected to nondescript ersatzism on these grounds (and thus branded it as 'magical'). ${ }^{1}$ Nondescript ersatzism is the view that possible worlds are structure-less abstract simples that represent in virtue of standing in the relation of selection to the concrete world. It is a metaphysic of modality that rivals, inter alia, linguistic ersatzism, pictorial ersatzism and modal realism. Lewis' critique of nondescript ersatzism is thought to solely consist in the following argument or dilemma:

(P1) Either the selection relation is internal or external. ${ }^{2}$

(P2) If the selection relation is internal, our concept of it is ungraspable, except by magic.

(P3) If the selection relation is external, it is magical.

(C) Thus, nondescript ersatzism should be rejected (because we should avoid magic).

The argument for (P2) is usually taken to be an argument that appeals to the fact that abstract simples are beyond our causal ken. Since these entities are out of our causal reach, we cannot identify which particular simple stands in the selection relation to the

\footnotetext{
${ }^{1}$ This view is usually called 'magical ersatzism'. I call it 'nondescript ersatzism' to emphasise the fact that it is the theory's property of being nondescript rather than being magical that is of most importance.

${ }^{2}$ Lewis considers 'further hypotheses' about selection only to put them aside as he '[does] not think they do any better' (Lewis 1986b, 182).
} 
concrete world being a certain way. Hence, we cannot understand how the selection relation holds between two things.

However, Lewis' allusion to the fact that abstract simples are beyond our acquaintance is not the main reason why he endorses $(\mathrm{P} 2)$. His argument for $(\mathrm{P} 2)$ is really an instance of the methodological strictures he imposes upon competing theories. In addition, Lewis' critique of nondescript ersatzism does not solely consist in the above dilemma. He also rejects nondescript ersatzism because it fails to adhere to his method in general. Once we understand his method we can understand the broader objection against nondescript ersatzism.

In what follows, I introduce Lewis' method $(\$ 2)$ and identify two underappreciated points $(\$ 3)$. I extract two rules from his method $(\$ 4)$, articulate nondescript ersatzism as understood by Lewis $(\$ 5)$, and present the above dilemma along with Lewis' real argument for $(\mathrm{P} 2)(\$ 6)$. I then unearth the broader objection against nondescript ersatzism $(\mathbb{S} 7)$ and demonstrate how it applies to differing versions of nondescript ersatzism $(\$ 8)$. I then consider replies on behalf of nondescript ersatzers and conclude that Lewis' objection remains a challenge $(\mathbb{S} 9)$. I end with some brief remarks about his method $(\mathbb{S} 10)$.

My aim is to articulate Lewis' broader objection within its context and restate it as a fresh challenge to nondescript ersatzers, alongside a restatement of Lewis' argument for (P2). Where appropriate I reject certain replies that have been made in defence of nondescript ersatzism. However, I do not provide a complete defence of Lewis. My approach is primarily exegetical. I wish to understand what exactly Lewis' critique is and examine its plausibility within the confines of a certain dialectic.

I assume Lewis' method or rather the aspect of it that I am discussing is correct. So, if a view violates his method, the view should be rejected. I do not think this assumption is too costly, although I admit we need a full exploration of his method. Henceforth, I call Lewis' method of metaphysics 'the method'. To clarify, I am not suggesting that Lewis followed the method explicitly and constantly. It was probably more of a tacit procedure that Lewis reasoned through in constructing his own views and grappling with others.

There are two limitations of my paper. The first limitation is that I do not consider replies to (P3) or discuss it beyond my presentation of Lewis' dilemma. Hence, I do not discuss replies that reject or amend Lewis' Humean denial of necessary connections between distinct entities (such as Zaragoza 2007, 394-400). The second limitation is that I do not discuss Peter van Inwagen's (1986, 207-10) tu quoque or dwell on the prospect that Lewis' critique is so powerful that it wreaks havoc across the enterprise of metaphysics. ${ }^{3}$

\section{Entities and Role-filling}

Lewis argued for his ontology of sets and possible worlds (and possible individuals or possibilia) by demonstrating its explanatory power. In order to demonstrate the ex-

\footnotetext{
${ }^{3}$ For Lewis' reply to van Inwagen, see (Lewis 1991, 35-38); see also (Melia 2008, 148-49). For the latter worry, see (Nolan 2015).
} 
planatory power of his theory he showed what work his ontology can do by filling specified roles. Lewis argued that his ontology can fill the many roles of properties, propositions, modality, content and much more. Given this explanatory power and the theory's theoretical elegance, we have reason to believe it is true.

Let us say roles are, following Lewis, 'in our commonsensical thought and in a variety of philosophical theories' (Lewis 1986b, 55). Let us also say, following Lewis, that words or names are associated with these roles. It might sound odd to say roles are 'in' our thought and 'in' our theories since it suggests roles are 'contained' in them somehow. But I think it is harmless. What I take Lewis to mean is that there are names in ordinary language or in a philosophical theory that pick out or stand for an entity that fills a certain role, just as in folk psychology we say mental state $M$ can be referred to as the occupant of the M-role. If ' $R$ ' is a name for an entity that fills a certain role (call it the R-role), then ' $\mathrm{R}$ ' just means 'the entity that fills the R-role'. Thus, to say that the R-role is 'in' our thought or 'in' a theory is to say that the word ' $R$ ' is associated with the R-role and is a name for the entity that fills this role. The role isn't really 'in' our thought or theory. It is a way an entity can be or what it does, so to speak. I revert to saying 'roles in our thought' in various places since the many quotations from Lewis below contain that phrase.

Roles need to be specified if we are to fill them with entities of certain kinds in our ontology because in many cases names such as 'property' are associated with several roles. As Lewis points out, there isn't just one 'property-role'(Lewis 1986b, 55). The property-role can be specified as the role of things being alike in a certain respect or as the role of things being the semantic value of abstract singular terms. Once specified, we fill it with entities of a certain kind that exist in our ontology. Similarly, the word 'proposition' is associated with certain roles in particular philosophical theories. These roles need to be specified before we can fill them with entities. One specification of the role of propositions is the role of accounting for their quasi-syntactic structure. The name 'proposition' is then associated with that specific role and as a result we have a distinct conception of propositions. We then fill this specific role with entities that we have independent reason to believe in.

I now borrow a useful distinction from van Inwagen to clarify the types of concepts that figure in, what I call, the 'functionalist' understanding of ontological explanation-where 'ontological explanation' just means the existence of entities explaining some fact that we think needs to be explained. Let us distinguish between functional and ontological concepts (van Inwagen 1986, 192). A functional concept is a concept of an entity that fills a particular role. For instance, the concept expressed by the term 'proposition' is typically understood as a concept of a thing that bears a truth-value. An ontological concept is a concept of a thing of a certain kind. The concept expressed by the term 'set' is a concept of a certain kind of thing. Given this distinction, the functionalist understanding of ontological explanation takes the basic concepts that we begin with in metaphysics as functional concepts. The concepts expressed by the terms 'number', 'proposition', and 'property' are functional concepts. These concepts are about things filling some role and not directly about things of a certain kind. In this sense, then, functional concepts are theory-neutral. Our job in providing an ontological explanation according to a metaphysical theory is to specify roles that are associated with certain names that express functional concepts and fill these roles with entities that are picked out by names that express ontological concepts. 
This is a bit hasty. The distinction between functional and ontological concepts is not wholly absolute. It is better understood as a distinction that is relative to a debate or explanatory goal. So, 'set' expresses an ontological concept relative to debates about properties or the goal of explaining resemblance, while 'set' expresses a functional concept relative to debates about the nature of sets. Perhaps we should say terms do not express an ontological or a functional concept simpliciter; but once we fix the context or debate we determinately fix what terms express a functional and ontological concept for that context or debate (cf. van Inwagen 1986, 193).

I do not think it is an accident that Lewis was attracted to the 'functionalist' understanding of ontological explanation. He always had 'functionalist' inclinations. Early on in his career, he defended a functionalist theory of mind (Lewis 1966, 17-18) and a functionalist definition of 'personal time' in order to solve the time-travel paradox of someone five minutes from now being two hundred years in the past (Lewis 1976, 146). These functionalist tendencies, I suspect, led Lewis (in part) to draw a distinction between the roles an entity performs and the entities that fill the role.

Why believe this functionalist understanding of ontological explanation? Here are two reasons in support of this approach. First, we can use it to solve the problem of metaphysicians talking past one another. To illustrate, philosophers have disputes about the metaphysics of propositions. Some people think they are mental acts; others think they are abstracta. But, in order for these parties to engage one another we need to understand their dispute such that there is one functional concept, namely, the concept expressed by the term 'proposition' that is associated with certain roles and then let the interlocutors proceed to argue about the nature of the entity that should fill that role and hence be the things we call 'propositions' (van Inwagen 1986, 193). Second, this understanding of ontological explanation shows us how a theory can possess explanatory power. Entities must earn their keep in our theory of what exists. If entities must be put to work, we need to specify what they do and talk about their function in our theory. The concept of entities filling roles captures the idea of our ontology doing explanatory work. Since this explains how a theory has or lacks explanatory power, we can gain an understanding of what it is for a theory to possess theoretical virtues such as simplicity, breadth, etc, which provide reasons to assign some degree of credence to a view.

\section{Role-fillers and their Nature}

Let us identify two underappreciated points that are relevant for understanding Lewis' aversion to magic. The first point is that entities filling roles does not provide grounds for the existence of particular kinds of entities that fill certain roles. Put differently:

Point 1 . For entities of kind $K$ to be role-fillers they must already exist in our ontology.

In Lewis' own case, he does not infer that sets exist from the fact that sets play the property-role. Rather, Lewis argues sets exist along Quinean lines and then says that since they exist, they can fill the property-role. Lewis writes, 
If we believe in possible worlds and individuals, and if we believe in set-theoretic constructions out of things we believe in, then we have entities suited to play the role of properties (Lewis 1986b, 50).

If these entities do not exist, we cannot use them as role-fillers; the things must exist before they can be put to work. We cannot argue they exist because they do all this work. That is why Lewis frames the question of role-filling as follows:

The question worth asking is: which entities, if any, among those we should believe in, can occupy which versions of the property role? (Lewis 1986b, 55).

Notice the qualification: 'among those [entities] we should believe in'. This qualification expresses the idea that we should independently believe in entities that we hope to use as role-fillers in our ontology. To be clear, Lewis does think '.. it is a firm commitment of common sense that there are some entities or other that fill the roles' (Lewis 1986b, 184). But this inference operates at the level of roles and at the level of functional concepts. We can argue from the existence of the property-role that there exist properties that fill this role, but we cannot argue from the existence of the property-role to a particular kind of property such as Aristotelian universals. We can fill the property-role with Aristotelian universals, but we need an independent argument for their existence. Here is another illustration and one that best explains Lewis' earliest argument for the existence of possible worlds. Consider the following:

It is uncontroversially true that things might be otherwise than they are. I believe, and so do you, that things could have been different in countless ways. But what does this mean? Ordinary language permits the paraphrase: there are many ways things could have been besides the way they actually are. On the face of it, this sentence is an existential quantification. It says that there exist many entities of a certain description, to wit 'ways things could have been'. I believe that things could have been different in countless ways; I believe permissible paraphrases of what I believe; taking the paraphrase at its face value, I therefore believe in the existence of entities that might be called 'ways things could have been' (Lewis 1973, 84).

A standard reading of this passage is that Lewis is arguing that there is a plurality of concrete universes with ours merely among the plurality. But this is not so. He is rather suggesting that 1 ) there is a role that we call 'ways things might have been' in ordinary language, 2) common sense suggests there are entities that fill this role, 3) thus, the entities that fill this role exist and are called possible worlds.

Why think that entities filling roles does not justify believing in entities of a certain kind? Why think that we must independently argue for entities of a certain kind and then have them fill certain roles? For one thing, the specification of roles is not a fixed and determinate matter. With respect to the roles associated with the word 'property', Lewis writes,

It's not as if we have fixed once and for all, in some perfectly definite and unequivocal way, on the things we call 'the properties', ... Rather, we have the word 'property', introduced by way of varied repertory of ordinary and philosophical uses. The word has thereby become associated with a role in our commonsensical thought and in a variety of philosophical theories (1986b, 55).

If the use of the word 'property' is not determinate, then just by saying there are entities that fill the property-role won't fix on a particular kind of entity. And if the role 
associated with 'property' needs to be refined and specified by us before we can give a conceptual analysis of the relevant notion, the issue of entities filling roles is not part of serious ontology. In addition, when we describe an entity as the filler of some role all we have provided is a theory-neutral description. We have said nothing about the nature of the entity that fills the role. So:

Point 2. The fact that entities fill roles does not determine the nature of those entities.

Consider this emphatic statement of (Point 2) by Lewis:

All this is a matter of fitting suitable entities to the various rather ill-defined roles that we rather indecisively associate with various familiar names. Don't think of it as a matter of discovering which entities really are the states of affairs, or the ways things might be, or the possibilities, or the propositions, or the structures! (Lewis 1986b, 186, his italics).

(Point 2) has historical precedent. Samuel Alexander implements (Point 2) as follows,

“A relation," says Mr. Russell (Principles of Mathematics, p. 95), "is a concept which occurs in a proposition in which there are two terms not occurring as concepts, and in which the interchange of the two terms gives a different proposition." This is however a description of relation by its function in a proposition, and is a purely logical generalisation; it does not profess to say what relations are in themselves (Alexander 1920, 171).

The intuitive thrust of (Point 2), in this instance, is that telling us what relations $d o$ won't tell us what relations are. Lewis and Alexander are in agreement on this point. Lewis says:

Our use of the names associates them in the first instance with roles in our thought. I suppose it is a firm commitment of common sense that there are some entities or other that fill the roles, and therefore deserve the names. But that is not to say that we have much notion what sort of entities those are (Lewis 1986b, 184).

Lewis says a few sentences later in a Quinean vein that we should determine the nature of the entities in our ontology by surveying 'the candidates according to our best systematic theory of what there is' (Lewis 1986b, 184). Giving an account of the natures of the role-fillers is independent of the fact that the roles get filled. The issue of rolefilling is more about us working out which words we associate with the roles in our thought and philosophical theories. This explains in part why Lewis should be understood as engaging largely in the project of conceptual analysis in metaphysics. He is attempting to explain our various concepts as expressed in ordinary language and thought, and our best philosophical theories; he is not endorsing robust metaphysical doctrines and analyses.

\section{Two Rules of Lewis’ Method}

From this talk of entities filling roles we can extract two rules that Lewis used in rejecting his opponent's theories. The first rule is extracted from Lewis' construction of his own theory of properties. On his view, a property is the set of all its instances throughout all worlds. The property being a donkey is the set of donkeys, where the 
members of this set include donkeys from all worlds. If sets of possible individuals exist and they fill the property-role, these sets deserve the name 'property'. Lewis says:

To deserve the name of 'property' is to be suited to play the right theoretical role; or better, to be one of a class of entities which together are suited to play the right role collectively (Lewis 1986b, 55).

He is committed to the rule that if entities of kind $K$ exist in our ontology and they fill role $R$, they deserve the name ' $R$ '. But he also thinks entities of kind $K$ cannot be labelled ' $R$ ' if they do not fill role $R$. So our first rule is:

Rule 1 . If entities of kind $K$ exist in our ontology, they deserve the name ' $R$ ' only if they fill role $R$.

If (Rule 1 ) is true, we cannot label the $K s$ ' $R$ ' just by the $K s$ bearing the name ' $R$ '. So:

Rule 2. If entities of kind $K$ exist in our ontology, they do not deserve the name ' $\mathrm{R}$ ' in virtue of the Ks being called ' $\mathrm{R}$ '.

These rules are employed in one of Lewis' objections against the late D.M. Armstrong's theory of laws of nature. On Armstrong's view, laws of nature are lawmaking universals that necessarily connect two first-order universals. Lewis writes,

What leads me (with some regret) to reject Armstrong's theory, whether with universals or with natural properties, is that I find its necessary connections unintelligible. Whatever $N$ may be, I cannot see how it could be absolutely impossible to have $N(F, G)$ and $\mathrm{Fa}$ without $\mathrm{Ga}$.... The mystery is somewhat hidden by Armstrong's terminology. He uses 'necessitates' as a name for the lawmaking universal $N$; and who would be surprised to hear that if $F$ 'necessitates' $G$ and $a$ has $F$, then $a$ must have $G$ ? But I say that $N$ deserves the name of 'necessitation' only if, somehow, it really can enter into the requisite necessary connections. It can't enter into them just by bearing a name, any more than one can have mighty biceps just by being called 'Armstrong' (Lewis 1983, $366)$.

Lewis argues that the lawmaking universal $N$ does not deserve the name 'necessitation' if it does not fill the role of necessarily connecting $F$ and $G$ (as per (Rule 1)), and that it cannot be called 'necessitation' by bearing that name (as per (Rule 2)). Lewis appeals to the Humean denial of necessary connections to argue that $N$ does not fill the role of necessarily connecting $F$ and $G$. So he concludes Armstrong's theory is wrong. Lewis also mounts the same argument against the magical conception of structural universals:

To name one universal 'methane' and the other 'carbon' ... is to name them descriptively, in other words tendentiously. To be sure, no two universals deserve those two names unless the first drags the second around with it; unless it is somehow necessary, inter alia, that every instance of the first contains an instance of the second as its central part. Of course. But our question is: how can two universals - universals understood as atomic - possibly deserve those two names? How can two universals, which we might at first call by the neutral names 'Matthew' and 'Carl', possibly enter into the necessary connection which would entitle us to call them 'methane' and 'carbon' instead? It only conceals our problem if we call them that from the start. The magician makes our problem vanish by verbal sleight of hand (Lewis 1986a, 42). 
A striking pattern about these objections is Lewis' insistence that we should, at the outset, introduce 'neutral' labels or names. We should not begin with loaded labels that mislead us into thinking we have identified the appropriate entity in our ontology as the appropriate role-filler. We start at the level of roles and begin with the mere fact that there are entities of some kind or other that fill yet to be specified roles. We see this recommendation made explicit when Lewis considers one (bad) reason to believe in Armstrongian states of affairs as follows.

Consider the particular $A$, the property $F$ and the claim that $A$ has $F$. For Armstrong, according to Lewis, there is a further entity which Lewis labels ' $B$ ' that exists iff $A$ has $F$. The entity labelled ' $\mathrm{B}$ ' is entirely distinct from $A$ and $F$. Lewis objects that $B$ cannot be necessarily connected to $A$ and $F$ (as per his Humean denial of necessary connections), but on Armstrong's view it is. Thus, Lewis rejects Armstrong's theory of states of affairs. Lewis considers the reply that the name ' $\mathrm{B}$ ' is 'a deliberately abstruse and alienating way' to introduce states of affairs. The more appropriate name, the reply continues, is 'the state of affairs of A's having F' (Lewis 1999, 216). However, Lewis says we are not entitled to label states of affairs in this way because if we do we are justifying the labelling of a particular entity in virtue of the entity bearing that name. This is a violation of (Rule 2).

There is a further restriction that comes from (Rule 1) interacting with (Point 2). Lewis thinks entities of kind $K$ deserve the name ' $\mathrm{R}$ ' if they fill role $R$ (as per Rule 1 ). But even if this is the case, it is no use telling us what entity it is in virtue of it filling this role. The reason for this constraint goes back to (Point 2). Role-filling does not tell us the nature of the entities being the role-fillers. All we are entitled to say is: 'this entity (which we already believe in) has earned the right to be called ' $\mathrm{R}$ "; and nothing more.

\section{Nondescript Ersatzism}

Nondescript ersatzers accept the following:

M. It is possible that $p$ iff there is a possible world according to which $p$.

So they need to do two things: 1) give an account of possible worlds and 2) give an account of how worlds represent. Let us begin with their account of possible worlds.

The ontology of nondescript ersatzism contains abstract simples and the concrete world that you and I occupy. Abstract simples are mereologically atomic, have no structure and are abstract in the Negative Way (i.e., $x$ is abstract iff $x$ is not a set, particular, equivalent class, universal, trope, or part of the concrete world). We are not told anything further about the nature of these elements or what they are like. Indeed, there isn't anything else to say about them. This denial is constitutive of the view.

Lewis calls the abstract simples of the nondescript's ontology 'elements'. He writes: 'You might prefer to give these simples some tendentious name, but I shall call them simply elements' (Lewis 1986b, 174, his italics). The method instructs him to say this because we should not label an entity descriptively at the outset in accordance with some role as we would be labelling an entity merely in terms of its functional concept; to name something descriptively is to name it tendentiously. 
We can however make some distinctions about how they are related to each other and the concrete world (hereafter, $w$ ). We need to introduce a real distinction between certain elements being a certain way when $w$ is a certain way. Lewis non-tendentiously labels the primitive relation that carves out this distinction 'selection'. Whether an element is selected is grounded in what the concrete world is like. If the concrete world contains Brownie the talking donkey, a certain element is selected. Elements can imply one another. If $w$ selects element $E$, then $w$ selects $F$. And if this is the case, then $E$ implies $F$. So, implication between elements is understood in terms of selection. We also get a Boolean algebra such that there are elements we call 'maximal' that are not implied by other elements. Alternatively, $E$ is a maximal element iff $E$ 'is incompatible with exactly those elements that it does not imply' (Lewis 1986b, 175). Only one maximal element is selected by $w$. If $w$ were different in some way, $w$ would select another maximal element. Ersatz worlds are a distinguished class of abstract simples. They are the maximal elements.

We can now give a non-structural account of representation as follows (a structural account, by contrast, appeals to the structure of the entities in one's ontology to explain how worlds represent):

R. It is the case that $p$ according to $E$ iff necessarily if $E$ is selected, then $p$.

On this view, we understand how worlds represent in terms of selection. If (R) is not taken to be a genuine account of representation, the nondescript ersatzer can say elements represent and that's that; they are primitive representational entities. Either way, selection is intimately connected with the notion of representation.

Lewis attacks nondescript ersatzism as formulated in two different ways. So we need to distinguish the variants of the view to understand his dilemma. The first variant includes all the positive aspects of nondescript ersatzism such as the fact that elements are abstract and simple and all the negative aspects such as the fact that elements have no structure and no nature. Let us label this variant 'NE'. The second variant includes all the positive aspects of $\mathrm{NE}$ and its negative claim that elements have no structure, but we add that each world has a distinctive intrinsic nature or unique intrinsic property. Let us label this variant ' $\mathrm{NE}^{+}$. Lewis' dilemma seeks to impale $\mathrm{NE}^{+}$on one horn and NE on the other. This dilemma is typically presented in the literature with its underlying methodological principles hacked off. ${ }^{4}$ Our aim in the next section is to present the dilemma without denuding it of its methodological principles.

\section{Lewis’ Dilemma}

Method is what drives Lewis' critique and sets the standards of intelligibility for our current debate. To gain an understanding of the selection relation we need a story about what makes $w$ being a certain way select this particular element and not another. So Lewis demands the nondescript ersatzer to classify their 'selects' ideology. Does the 'selects' predicate pick out an internal or external relation? ${ }^{5}$ If it is internal, it holds

\footnotetext{
${ }^{4}$ (Denby 2006, 163-66; Hymers 1991, 253-54; Zaragoza 2007, 391-94) ignore the methodological premises when they present this objection.

${ }_{5}^{5}$ You might think there is no relation realistically conceived as an entity; the two-place predicate '... selects ...' is a piece of primitive ideology that does not correspond to an entity in the ontology of the
} 
between $w$ and a particular element in virtue of $w$ being a certain way and the element having a unique intrinsic nature or property. The being taller than relation can only hold between you and me if we have respective heights. If I were $188 \mathrm{~cm}$ tall and you were an abstract simple with no nature, the 'taller than' relation could not hold between us. Now, if the nondescript ersatzer posits elements with intrinsic natures, we are told something positive about their nature. Each element has a distinctive intrinsic property that determines in part whether it is selected by $w$. So, if selects is internal, we are dealing with $\mathrm{NE}^{+}$. Lewis objects to $\mathrm{NE}^{+}$by invoking the method as follows:

There is an element such that, necessarily, it is selected iff a donkey talks; that element has some distinctive intrinsic property; that property is named 'representing that a donkey talks'; the property with that name singles out the element that, necessarily, is selected iff a donkey talks. Not a thing has been said about what sort of property that might be; still less, about which property of the appropriate sort it might be. The property that plays the role is: the property that plays the role (Lewis 1986b, 178).

Friends of $\mathrm{NE}^{+}$have labelled an entity (in this case, a property) using the role that it is stipulated to fill. In short, they have violated (Rule 2). As per (Point 2), just telling us which entity fills which roles does not tell us anything about the nature of the entity. Lewis continues: 'It is no use telling me by name what property it is, if it bears that name exactly because it plays the role' (Lewis $1986 \mathrm{~b}, 178)$. Therefore, we have no notion or concept of what these intrinsic properties are. We do not have an account of their nature by identifying them through their roles. Since we have no account of their nature, we have no concept of their nature. So, we have no concept of how the selects relation holds between elements and the concrete world. Therefore, if the selects relation is internal, our concept of it is unintelligible; and the label 'selects' could not be 'our word for any such relation' (Lewis 1986b, 182). ${ }^{6}$

My interpretation of the first horn did not say anything about us failing to have any causal contact with these intrinsic properties and that that was the reason why we could not understand why the relation holds and therefore fail to grasp the concept of 'selects'. Lewis' claim that we cannot name the intrinsic properties of elements because most of them are beyond our ken is, in my view, a subsidiary point. It is not the core

theory. So, it makes no sense to say that the relation is not graspable or magically connects the concrete world and elements. However, the issue is not really to do with relations as entities. It is about our concept of selection that is expressed by the predicate 'selects' (this is so even in the case of the selection relation being external). If you deny the existence of the relation, you still have the predicate and hence must give an account of how we grasp the concept expressed by that predicate.

${ }^{6}$ David A. Denby says in reply to Lewis that we can grasp the selects relation by positing a further primitive that pairs properties of elements with properties of the world. The world being $\mathrm{P}$ selects element $\mathrm{E}$ being Q iff some P and some Q stand in the pairing relation $\mathrm{R}$ to each other and the world is $\mathrm{P}$ and element $\mathrm{E}$ is $\mathrm{Q}$ (Denby 2006, 167). So we do not need to grasp particular properties of elements; rather, the reply goes, we need only grasp the Q-properties in general via quantification over them. However, this proposal is misguided. To label the property $Q$ as a ' $Q$-property' is to commit the error of describing an entity in terms of the role it fills. It is pointless to tell us this property is called ' $Q$ ' and that this is what property it is because it plays the Q-property-role. We have no notion of what a property called ' $Q$ ' is beyond the fact that it plays the Q-property-role. You might reply on behalf of Denby that he hasn't described or named the Q-properties; instead, he has quantified over them. Even still, to quantify over Q-properties we require in our fundamental ideology the predicate '... is a Q-property' in sentences like: 'there is an $x$ such that $x$ is a Q-property'. We need a predicate like this to demarcate the Qproperties from the P-properties. We are confronted with our original problem. 
of his argument for the first horn, nor is it the main reason why we have no notion of 'selects'.

Let us consider the second horn of the dilemma. It begins with the claim that selects is external. In presenting the second horn Lewis reverts back to the initial denials of nondescript ersatzism. After all, the positive suggestion that elements have unique intrinsic natures was to render the selects relation internal. If we do not think the selects relation is internal, there is no reason to say elements have unique intrinsic natures. So we are dealing with NE. According to NE, the elements are all alike and are related analogously to how points are spatially related by distance in a manifold. The arrangement of the elements in their relational system is necessarily connected with $w$. If $w$ is a certain way, $w$ selects those elements; if $w$ is a different way, $w$ selects these elements. To reiterate, the relation of selection does not hold in virtue of the intrinsic natures of the elements. None of them have an intrinsic nature on this proposal. But still the selects relation holds between certain ways the world can be and certain elements in a particular arrangement. NE involves primitive necessary connections that are metaphysically repugnant. If selects is external, nondescript ersatzism violates the Humean denial of necessary connections (Lewis 1986b, 181). Thus, the relation of selection is unintelligible.

\section{The Magicians’ Protest and Lewis’ Broader Objection}

After giving the dilemma just sketched Lewis considers a rejoinder on behalf of nondescript ersatzers. It is here that Lewis provides a further argument within the spirit of his argument for (P2) but directed at the very approach espoused by nondescript ersatzers. Let us call it 'the broader objection'. The broader objection has not been adequately discussed in the literature. Most of the discussion has been centred on Lewis' dilemma.

Lewis begins with the following protest by nondescript ersatzers. They say 'selects' is not the right label for the relation; using the word 'selects' is 'a deliberately abstruse and alienating way' to label a relation that should be called, say, 'makes true'. They further note the word 'elements' is similarly misplaced; we should replace it with 'propositions' and say propositions are made true by $w$. Only by doing this can we understand the theory's primitives. This is how van Inwagen $(1986,201-02)$ sets out his version of nondescript ersatzism.

Lewis replies that this rejoinder violates the method as follows. First, we should not introduce a descriptive label tendentiously when constructing the theory because if we do we are saying certain entities have the label, say, 'propositions' or fill a certain role solely in virtue of these entities bearing the name 'proposition'. So, nondescript ersatzers cannot use terms such as 'proposition' and indeed 'makes true' at the outset. Second, the words 'proposition' and 'state of affairs' are associated with many different roles in our commonsensical thought and philosophical theories. Lewis says, '[o]ur use of the names associates them in the first instance with roles in our thought'

\footnotetext{
${ }^{7}$ Since his objection here does not rest on the relevant intrinsic representational properties being beyond us causally, the reply that we can know these properties by inference to the best explanation does not directly address the issue.
} 
(1986b, 184, my italics). These names, in effect, express functional concepts. Therefore, Lewis says, all you have done is picked out a role using its corresponding functional concept, specified the role accordingly and then declared that states of affairs or propositions fill this state-of-affairs-role or this proposition-role. However, given (Point 2), the fact that an entity fills a role does not tell us anything about its nature. So, if you say these entities fill the role of being representational elements, you have provided no explanation of the notion or concept of their nature. Therefore, we have no explanation of how the appropriate relation holds between these particular entities and not others. So, we cannot grasp the primitives of nondescript ersatzism. Third, we cannot identify which entities in our ontology play the appropriate role in virtue of the fact that they play a certain role. Lewis writes,

It's no good saying: which are they? - why, they are the states of affairs! (Or the ways things might be, or ....) You might as well interrupt a serious discussion of how to cast a play and say: who shall be Polonius? - Let it be Polonius! (Lewis 1986b, 184).

Lewis' point is that we cannot determine which entities fill the ways-things-might-berole in virtue of identifying entities solely through their act of filling the ways-thingsmight-be-role. Entities that are picked out by terms that express functional concepts cannot fill the appropriate role because the role itself is understood in terms of the same functional concept. Nondescript ersatzism violates the method and so, according to Lewis, should be rejected.

\section{This-worldly Nondescript Ersatzers}

Lewis presents the above rejoinder and the broader objection with various defenders of nondescript ersatzism in mind. Lewis mounts the broader objection against two versions of nondescript ersatzism that have been endorsed in the literature. The first version takes possible worlds as primitive and reduces propositions to possible worlds (or identifies propositions with possible worlds). The second version takes propositions or states of affairs as primitive and defines up possible worlds. Michael A. Slote (1975, 147-48) and Robert C. Stalnaker (1976, 70-75; 1984, 50-58) constitute the first camp. Alvin Plantinga $(1974,44-45)$ and van Inwagen $(1986,201-02)$ constitute the second camp.

These versions of nondescript ersatzism are distinct and competing theories of modality. Stalnaker, for instance, is keen to not only reject Lewis' modal realism but also Robert Merrihew Adams' (1974, 225-26) analysis of possible worlds in terms of sets of propositions. ${ }^{9}$ Adams thinks that to avoid modal realism we need to reduce possible

\footnotetext{
${ }^{8}$ According to Slote, propositions are to be identified with possibilities, as per Ockham's razor (Slote 1975, 148). One example: ' $[t]$ he proposition that Helen is white at $t$ is, on our view, the logical possibility that Helen is white at $t$, or, perhaps, alternatively, the logical possibility of Helen's being white at $t$ ' (Slote 1975, 150). The proposition that $p$ is true is the possibility of $p$ being realised. A possible world is thus a maximal possibility. Properties are also identified with possibilities (Slote 1975, 154). What it is for $a$ to have $F$ is for the possibility that $a$ is $F$ to be realised. States of affairs, propositions and properties are all identified with primitive possibilities. Even necessary propositions are accounted for; they are possibilities that must be realised (Slote 1975, 153).

${ }_{9}$ Although Lewis does not mention Adams in his list of nondescript ersatzers on p. 183 of (1986b), it seems reasonable to include Adams in the second camp.
} 
worlds to sets of propositions. Stalnaker insists there is a third way: identify possible worlds with ways things might have been. He asks:

Why cannot ways things might have been be elements of the actual world, as they are? (Stalnaker 1976, 70).

Lewis' answer is that we cannot take ways things might have been as primitive elements of the actual world because to say ways things might have been are entities that fill the ways-things-might-be-role is to fill a role with an entity that can only be picked out via the role that it is purported to fill. Hence, the broader objection applies to Slote and Stalnaker. Do members of the second camp commit the same methodological error? Plantinga approaches the topic ab initio as follows:

So we must ask initially what sort of thing a possible world is. The first and rough answer is that it is a way things could have been; it is a way the world could have been; it is a possible state of affairs of some kind (1974, 44, his italics). ${ }^{10}$

Plantinga therefore thinks that a possible world is a way things might have been or a possible state of affairs. For van Inwagen, a possible world is a 'maximal possible proposition' $(1986,201)$. However, there is no genuine reduction or analysis here beyond stating that 'a way things could have been' is a phrase similar in content to 'a possible state of affairs' or 'a possible proposition' and that entities that are picked out by the former phrase can be picked out by the latter phrase.

For Plantinga and van Inwagen to give a substantive account of possible worlds that employs a genuine ontology they need to identify or reduce possible worlds to entities in their ontology. Plantinga's preferred ontology contains maximal possible states of affairs that are necessarily abstract and can obtain or not obtain. Plantinga thinks it is obvious that states of affairs exist (Plantinga 1976, 143). Ordinary examples such as Quine's being an Emersonian are meant to suggest the existence of states of affairs. Since they exist, he thinks they fill the possible-worlds role (with the introduction of inclusion and exclusion relations between states of affairs). van Inwagen also needs an independent argument for an ontology that contains maximal possible propositions of a specific kind and can be picked out without using a name that merely expresses a modal functional concept.

As per the method, Lewis would first reply that Plantinga has only given an argument for the existence of entities of some kind or other that fill certain roles. Plantinga cannot conclude that his specific necessarily existing abstracta exist given his argument. Plantinga has merely introduced a phrase that expresses a functional concept. Lewis would further say because Plantinga has not determined any role-filler he cannot use the concept he has identified as part of his analysis of possible worlds. We cannot give an analysis of possible worlds in terms of possible states of affairs because their corresponding terms express (more or less) the same functional concept. Moreover, if we say these possible states of affairs or these possible propositions are the possible worlds, then we have said, in effect, that possible worlds play the possible-worlds-role and picked out the entities we want to call 'ways things might have been' merely through the ways-things-might-be-role. The same criticism applies to van Inwagen. His

\footnotetext{
${ }^{10}$ Consider a similar thought expressed elsewhere by Plantinga: 'Possible worlds themselves are typically 'taken as primitive', as the saying goes: but by way of informal explanation it may be said that a possible world is a way things could have been - a total way' (Plantinga 1976, 139, his italics).
} 
concept of a maximal possible proposition is also functional. As he admits, '... the concept of a proposition is the concept "bearer of truth-value" (1986, 193). Lewis would say that the method applied to van Inwagen's nondescript ersatzism yields the verdict that we have no concept of their nature or how they represent. Thus, the broader objection applies to Plantinga and van Inwagen.

To follow the method we need to argue for entities of a certain kind independent of the functional concept of a possible world. And in positing these entities (with good reason) in our ontology we will be able to pick them out using a term that expresses an ontological concept. After introducing a predicate into our ideology that expresses the appropriate ontological concept, we specify the functional concept of a possible world, a possible state of affairs, or a way things might have been and then fill it with the entities that are picked out by the term that expresses the ontological concept.

In On the Plurality of Worlds, Lewis labels Peter Forrest as a nondescript ersatzer (Lewis 1986b, 183). But Forrest is not really a nondescript ersatzer because he follows the method. According to Forrest (1986, 16-21), ersatz worlds are uninstantiated structural universals. The concept of a universal is a concept of a thing being a certain kind relative to the debate about the nature of possible worlds. Hence it is an ontological concept for our current purposes. Forrest fills the possible-worlds-role with entities that are picked out by a term that expresses an ontological concept. He gives us a theory about the nature of possible worlds without identifying the role-fillers through the role they are supposed to fill. Forrest's theory of ersatz worlds is a genuine competitor to Lewis's modal realism. They agree on what the functional concept is and disagree about what the nature is of the entities that fill the possible-worlds-role. In 'Against Structural Universals', Lewis admitted that Forrest should not have been labelled a nondescript ersatzer (Lewis 1986a, 25). Lewis had no objection to Forrest's use of structural universals; they are genuine candidates for the ways-things-might-be-role. So, Lewis had to attack the nature of structural universals. This is confirmed in a letter by Lewis to T.L.S. Sprigge:

If I believed in complex structural universals, one of which is the total nature of the actual world, and the rest of which could have been, then I might be willing to join you and others in identifying these structural universals with (at least some of) the possible worlds. I resist not the identification, but rather the structural universals themselves. I have trouble making sense of the relation between a structural universal and the simpler universals which are its constituents (Letter by Lewis to Sprigge, 15 November 1993). ${ }^{11}$

In sum, Forrest does two things distinct from nondescript ersatzers. First, he employs an ontology that is constructed independently from its application to the metaphysics of modality. Second, the entities he fills the ways-things-might-be-role with have a certain kind of structure that underpins his account of how worlds represent. Forrest, like Lewis, correctly follows the method. Nondescript ersatzers do not; their view should not be accepted.

\footnotetext{
${ }^{11}$ For recent replies to Lewis' objection against the mode of composition enjoyed by structural universals, see (Bennett 2013; Hawley 2010). Thanks to Steffi Lewis for permission to publish this excerpt from a letter by Lewis.
} 


\section{Replies to Lewis’ Broader Objection}

Let us consider some replies to the broader objection. My discussion of these replies is not decisive. My goal is to discuss the relevant issues and responses so that we can see how the debate should move forward.

The first reply you might consider is that Plantinga and other nondescript ersatzers can, after all, construct a distinct ontological concept that defines up entities that fill the possible-worlds-role. For instance, van Inwagen says that on Plantinga's view ' $x$ is an A-world $=\mathrm{df} x$ is a possible state of affairs (one that possibly obtains), and the conjunction of $x$ and any state of affairs that $x$ does not include is not a possible state of affairs' (van Inwagen 1986, 187). The predicate '... is an A-world' expresses an ontological concept, namely, the concept of the kind of thing that is an A-world. Thus, Plantinga is not employing a functional concept expressed by 'possible world' or 'ways things might have been'. There are two ontological concepts of possible worlds (Lewis' concrete worlds and Plantinga's A-worlds) and they are genuine candidates for filling the possible-worlds-role So, the reply concludes, Lewis' broader objection misses its target.

However, Lewis will insist 'possible worlds' and 'possible states of affairs' express the same functional concept, or at the very least, Plantinga's definition appeals to or uses the functional concept of a possible world. Hence, the concept of an A-world is not solely about an entity of some kind and is therefore not an ontological concept. To be fair, this reply on behalf of Lewis employs an assumption that is reminiscent of his reductive ambitions of explaining the modal in terms of the nonmodal. Lewis' reductive programme seems to require genuine competitors to employ a nonmodal ontological concept that is distinct from modal functional concepts. The force of his objection hinges on whether or not we endorse his reductive standards.

The second reply involves arguing independently for the existence of possible propositions, possible states of affairs, or possible worlds. This would provide an independent reason to believe in the entities nondescript ersatzers want to fill the possible-worlds-role with. If these arguments get us the entities we need and we can pick them out with names that express ontological concepts, we can fill the possibleworlds-role with these entities. Some independent arguments for these entities stem from meta-logical issues in modal logic and possible-world semantics. Others appeal to the fact that we need propositions or states of affairs to fill the role of being the meaning of our sentences/expressions and the role of being the content of our beliefs. But there are two problems with these arguments.

First, the arguments that derive from meta-logical issues only involve concepts about what a thing does with respect to modal statements (such as Stalnaker 1984, 57). So, these arguments won't deliver the kinds of entities we need to provide a theory about the nature of possible worlds. We are, in effect, stuck at the level of roles and forever move between functional concepts that do not provide the sort of ontological explanation the method is asking for. Some philosophers may accept this result. Stalnaker would be attracted to it because he has a pragmatist prejudice that is incompatible with full-blooded metaphysical realism. Other nondescript ersatzers won't accept this result because they wish to maintain full-blooded metaphysical realism. This is one place where the dispute can progress. 
Second, the other arguments for propositions and states of affairs (let us bracket possible worlds as primitive entities here) posit entities with a structure that involves concrete individuals, properties and relations or (Fregean)-concepts of such things as constituents. But these are not the sorts of propositions available for the nondescript ersatzer. Their propositions have no structure and so cannot be constituted by concrete individuals, properties or relations or constituted by concepts of such things. The propositions or states of affairs of nondescript ersatzism need to be necessary beings existing as structure-less simples with no natures or if we accept $\mathrm{NE}+$ with unique primitive natures.

Michael Jubien thinks, in contrast to my suggestion, that Lewis' objection rests on the assumption that the abstract entities of the ontology of nondescript ersatzism are simple, but that since any argument for these kinds of entities must regard them as complex, they would have an inner structure that plays the role of representing what might have been the case and that their complexity would help fill the ways-thingsmight-be-role. Jubien concludes that since the nondescript ersatzer should reject the assumption that the requisite abstracta are simple they can reject Lewis' critique (Jubien 1991, 266-67).

But I fail to see how Jubien's conclusion is a direct response to Lewis. The claim that possible worlds qua abstract simples cannot be an acceptable theory of modality is precisely what Lewis' critique proves. In one sense Lewis would agree with Jubien. What they disagree on is what we should infer from this claim. Jubien assumes this is a respectable amendment of nondescript ersatzism. But Lewis would infer that we have modified the theory such that it is no longer nondescript and so endorsed some other kind of ersatzism. For it provides a structural as opposed to a non-structural account of representation and a theory about the nature of possible worlds that appeals to the structure of the entities that fill the ways-things-might-be-role. If Jubien thinks we must accept that we cannot achieve a non-structural account of representation, he has embraced and not rejected the conclusion of Lewis' critique. Furthermore, it is wrongheaded to say that Lewis is unfairly assuming that the nondescript ersatzer posits abstracta with no structure. Nondescript ersatzers, as we have seen, do not give any account of the nature or structure of the abstract entities of their ontology. Plantinga says nothing about the structure of his states of affairs, nor does van Inwagen say anything about the structure of the propositions he believes in. Slote and Stalnaker are also in the same boat because they give no account of possibilities besides the claim that they are abstract. Thus, Jubien cannot accuse Lewis of misrepresenting his opponents.

If the proponent of nondescript ersatzism recognises that they must give an account of possible worlds that involves entities with structure, Lewis would query the structure of these entities in the same way that Lewis objected to the nature of structural universals when criticising Forrest's theory. If you take the structure of possible states of affairs or propositions as primitive, (and you may be motivated to say this because the entities that allegedly have structure are primitive) Lewis would say you are admitting abstract structural entities that are composed somehow of simpler parts or constituents. But how this happens he would argue is unintelligible as the only mode of composition he understands is mereological. We can question whether there is more than one mode of composition. This is another place where the debate may progress. 


\section{Conclusion}

Lewis' method embodies one conception of ontological explanation. His concern however extends beyond this. He thinks his method yields a standard about when a notion or concept is intelligible and so able to be grasped by us. The "standards of intelligibility" are about how certain facts obtain and not about what facts obtain or that a certain set of facts obtains. In his rejection of the magical conception of structural universals, Lewis writes,

It ought to be child's play to formalise this conception systematically in a suitable modal language. And that is all that many philosophers would ask. But that just goes to show that their standards of intelligibility are incomplete. Although we understand just what necessary connections are supposed to obtain, we are given no notion how they possibly could (1986a, 42).

Lewis understands what connections obtain according to his opponent's theory. $\mathrm{He}$ understands that there needs to be a connection of metaphysical necessity between being carbon and being methane. But the standards of intelligibility that derive from his idea of entities filling roles compel us to understand a theory's primitive by understanding how it holds between some entities and not others. With respect to nondescript ersatzism, Lewis understands what selects does. But his standards of intelligibility require us to understand how selects does what it does. And this he argues we cannot understand and so concludes we cannot grasp the concept of selects or the relation of selection. ${ }^{12}$

The chief reply to Lewis is to question the justification of Lewis' method and proceed to reject his rules of role-filling. One reply directed at me is to question whether Lewis' aversion to magic is an instance of an over-arching method or merely a stricture against committing what he thinks is a grave mistake in metaphysics. Now, I assumed he tacitly adhered to (what I am calling) the method and that the method was correct. I do not have space to discuss it beyond my explication in previous sections. It is a topic of another paper and indeed a research project that ought to explore the origins of his method, its components and its many applications to various metaphysical theories.

Acknowledgements Thanks to Peter Forrest for discussion and Steffi Lewis for permission to publish an excerpt from a letter by David Lewis. I am grateful to the British Academy for a Newton International Fellowship and the John Rylands Research Institute in Manchester, UK for research support.

\section{References}

Adams, Robert Merrihew. 1974. Theories of Actuality. Nô̂s 8(3): 211-31.

Alexander, Samuel. 1920. Space, Time, and Deity: The Gifford Lectures at Glasgow 1916-1918 (vol. 1). London: Macmillan.

\footnotetext{
${ }^{12}$ Jubien $(1991,265-66)$ says Lewis thinks that the phrase 'the proposition that p' does not pick out a specific proposition and that the phrase 'representing that p' does not refer to a specific representing property had by an element. But this is not entirely correct. Lewis says they can be named but thinks nondescript ersatzers must provide a story about how this is so.
} 
Bennett, Karen. 2013. Having a Part Twice Over. Australasian Journal of Philosophy 91(1): 83-103.

Denby, David A. 2006. In Defence of Magical Ersatzism. Philosophical Quarterly 56(223): 161-74.

Forrest, Peter. 1986. Ways Worlds Could Be. Australasian Journal of Philosophy 64(1): 15-24.

Hawley, Katherine. 2010. Mereology, Modality and Magic. Australasian Journal of Philosophy 88(1): $117-33$.

Hymers, Michael. 1991. Something Less Than Paradise: The Magic of Modal Realism. Australasian Journal of Philosophy 69(3): 251-63.

Jubien, Michael. 1991. Could This Be Magic? Philosophical Review 100(2): 249-67.

Lewis, David. 1966. An Argument for the Identity Theory. Journal of Philosophy 63(1): 17-25.

-. 1973. Counterfactuals. Cambridge: Harvard University Press.

-. 1976. The Paradoxes of Time Travel. American Philosophical Quarterly 13(2): 145-52.

- 1983. New Work for a Theory of Universals. Australasian Journal of Philosophy 61(4): 343-77.

-. 1986a. Against Structural Universals. Australasian Journal of Philosophy 64(1): 25-46.

- 1986b. On the Plurality of Worlds. Oxford: Basil Blackwell.

-. 1991. Parts of Classes. Cambridge, MA: B. Blackwell.

-. 1999. A World of Truthmakers? In Papers in Metaphysics and Epistemology, ed. D. K. Lewis. Cambridge: Cambridge University Press.

Melia, Joseph. 2008. Ersatz Possible Worlds. In Contemporary Debates in Metaphysics, ed. T. Sider, J. Hawthorne and D. Zimmerman. Blackwell.

Nolan, Daniel. 2015. It's A Kind of Magic: Lewis, Magic and Properties. Synthese doi: 10.1007/s11229014-0565-4.

Plantinga, Alvin. 1974. The Nature of Necessity. Oxford: Clarendon Press.

-. 1976. Actualism and Possible Worlds. Theoria 42(1-3): 139-60.

Slote, Michael A. 1975. Metaphysics and Essence. Oxford: Basil Blackwell.

Stalnaker, Robert C. 1976. Possible Worlds. Noûs 10(1): 65-75.

-. 1984. Inquiry. Cambridge, MA: MIT Press.

van Inwagen, Peter. 1986. Two Concepts of Possible Worlds. Midwest Studies in Philosophy 11: 185213.

Zaragoza, Kevin. 2007. Bring Back the Magic. Pacific Philosophical Quarterly 88(3): 391-402. 